Original Article

\title{
Causes of Maxillofacial Injuries in Patients Reporting at Liaquat University Hospital Hyderabad
}

\author{
Razia Sultana, Qamer un Nisa, Muhammad Rizwan Memon, Shahnila Shaikh
}

\begin{abstract}
OBJECTIVES: To determine the causes of maxillofacial injuries in patients reporting at Dental outpatient department of Liaquat University Hospital Hyderabad.

METHODOLOGY: This descriptive study was carried out from January 2014 to December 2015, at the outpatient department of Oral Surgery. Data relating to 136 patients of maxillofacial trauma was collected. The causes of trauma were asked from the patients and attendants. The diagnosis of the maxillofacial trauma was done on the basis of history, clinical findings and with the help of appropriate radiographs. All the relevant information was recorded in structured Proforma.

RESULTS: Most prevalent age of trauma was 21-30 years, male $(n=104,76 \%)$ outnumbered the female $(n=32,24 \%)$ with ratio of 3:1.The commonest cause of maxillofacial fractures was found to be Road Traffic Accidents (RTA) in 59(43.4\%) cases, followed by assault 44(32.4\%), fall injuries $12(8.8 \%)$, sports injuries $11(8 \%)$ and gun shot and others in $10(7.4 \%)$.

CONCLUSION: Road Traffic Accidents, in this part of the country, are the most common cause of maxillofacial fractures. Vehicle's poor condition, heavy traffic load and poor condition of roads are major contributing factors. There is a clear need of continues awareness of road user about the traffic rules, road safety and compulsory seat belt for four wheel vehicle passengers and helmet legislation for front as well as back seat motorcycle passengers.
\end{abstract}

KEY WORDS: Trauma, Injury, Maxillofacial injury, Maxillofacial trauma.

This article may be cited as: Sultana R, Nisa Q, Memon MR, Shaikh S. Causes of Maxilofacial Injuries in Patients Reporting at Liaquat University Hospital Hyderabad. J Liaquat Uni Med Health Sci. 2017;16(01):17-9. doi: 10.22442/jlumhs.171610499

\section{INTRODUCTION}

Maxillofacial fractures are 2nd most common injuries after head injuries presenting facial bone fracture ${ }^{1}$. Fracture of the face have been recognized for a long time, the Hippocrates was first, who described etiology and treatment modalities ${ }^{2}$.

The frequency of facial injuries is high because face is an exposed part of the body, the midface fracture involved the facial skeletons central section, to which the mandible inferiorly and frontal bone is attached superiorly. The highest incidence of maxillofacial fractures was found to be in the third decades of the life and lowest in the seventh decade, mostly younger peoples are involved due to motor vehicle collisions in rush areas ${ }^{3}$.

The causes of maxillofacial fractures vary from country to country and it is evident that some of the variation can be attributed to social, cultural and environmental factors ${ }^{4}$.Von hoof et $\mathrm{al}^{5}$ analyzed pattern of facial skeleton fractures in four European countries and observed considerable variations. Alcohol and drugs abuse are major factors in the etiology of traumatic injuries in developed countries. Maxillofacial injuries are common in young man than other age groups and to a large extent this is a reflection of increased of alcohol consumption by this section of the society in developed countries ${ }^{6}$ On the other hand in developing countries with a rapid increase in road traffic motor vehicle related trauma is the major cause of facial trauma ${ }^{7}$.

Etiology of facial trauma is continuously changing. This is the result of change in our life style due to modernization and mechanization worldwide. With the help of this study, we tried to find out the common causes of maxillofacial injuries in this part of country. This study may provide ground for recommendation of possible preventive measures for example compulsory use of helmet and seat belt legislation in our country.

\section{SUBJECT AND METHODS}

This descriptive observational study was carried out from Jan 2014 to Dec 2015, at outpatient department of Oral Surgery; Liaquat University Hospital Hyderabad by using Convenience (non-probability) sampling technique. The ethical approval was taken from the ethical review committee of the institute. Total 136 adults patients from either genders with clinically evident sign and symptoms of facial bones fractures and with radiographic evidence were 
included in this study. Patients reporting after one month of injury and patients presented with other associated facial skeletal fractures were excluded.

The causes of trauma were asked from the patient and their attendants. The diagnosis of the maxillofacial trauma was done on the basis of history, clinical findings and with the help of appropriate radiographs. All the relevant information was recorded.

Data analysis was done in statistical program for social sciences (SPSS) version 21.0 on computer. Descriptive statistics was calculated. Frequency and percentages and ratio for gender was calculated. The frequency and percentage were also calculated for qualitative variables (maxillofacial injury causes).

\section{RESULTS}

A total of 136 patients were included in this study. The gender distribution showed male predominance to female, male $n=104(76 \%)$ and female $n=32(24 \%)$, with overall ratio of $3: 1$. Mostly younger patients were victim of road traffic accident $(20 \%)$ as shown in table I.

The distribution to the causes of maxillofacial trauma shows Road Traffic Accidents (RTAs) constituted 59 $(43.4 \%)$ of injuries, followed by assault $44(32.4 \%)$, fall injuries $12(8.8 \%)$, sports $11(8.0 \%)$, gun shot and others $10(7.4 \%)$ details are shown in Table II.

TABLE I:

AGE AND GENDER DISTRIBUTION ( $n=136)$

\begin{tabular}{|c|c|c|c|c|}
\hline $\begin{array}{c}\text { Age group } \\
\text { (years) }\end{array}$ & Male & Female & Total & $\%$ \\
\hline $1-10$ & 7 & 01 & 8 & $6 \%$ \\
\hline $11-20$ & 13 & 05 & 18 & $13 \%$ \\
\hline $21-30$ & 21 & 07 & 28 & $20 \%$ \\
\hline $31-40$ & 20 & 07 & 27 & $19 \%$ \\
\hline $41-50$ & 16 & 04 & 20 & $15 \%$ \\
\hline $51-60$ & 13 & 04 & 17 & $13 \%$ \\
\hline $61-70$ & 07 & 02 & 09 & $7 \%$ \\
\hline $70-80$ & 07 & 02 & 09 & $7 \%$ \\
\hline TOTAL & $\mathbf{1 0 4}$ & $\mathbf{3 2}$ & $\mathbf{1 3 6}$ & $\mathbf{1 0 0} \%$ \\
\hline
\end{tabular}

Ratio of Male and Female 3:1

\section{DISCUSSION}

The results of this study showed that most common cause of maxillofacial injury is the road traffic accident $\mathrm{n}=59(43.4 \%)$. The gender distribution of the reported cases showed that male were $104(76 \%)$ and female were $32(24 \%)$. This $3: 1$ ratio of male preponderance
TABLE II: ETIOGY OF FRACTURE $(n=136)$

\begin{tabular}{|l|c|c|}
\hline \multicolumn{1}{|c|}{ Etiology } & No. of Etiology & Percentage (\%) \\
\hline RTA & 59 & $43.4 \%$ \\
\hline Assault & 44 & $32.4 \%$ \\
\hline Fall injury & 12 & $8.8 \%$ \\
\hline Sports & 11 & $8.0 \%$ \\
\hline Gunshot \& Others & 10 & $7.4 \%$ \\
\hline Total & $\mathbf{1 3 6}$ & $\mathbf{1 0 0 \%}$ \\
\hline
\end{tabular}

can be explained by the fact that the young male adults are more actively involved in outdoor activities during this period of life e.g. social activities, sports, high speed transportation etc. This makes male subjects more vulnerable due to their dominant role in outdoor activity. Whereas in rural areas where illiteracy is more, assault and Karokari revenge is more prevalent affecting females. Male female ratio of our study is in agrrement as reported by Abbas $^{8}$, Adebeyo $\mathrm{EO}^{9}$ and Zakai $\mathrm{MA}^{10}$. However it is different from reported by Bataineh $A B^{11}$. The predominant age group affected were between 21 to 30 years. This result is almost same as previous studies done by Abbas $^{8}$ and Cheema $^{12}$. The causes of maxillofacial trauma have changed over the last three to four decades and this was observed due to increasing cases of bomblast in our region. The current cases of the fracture of facial bones are interpersonal violence, sports injuries, falls and more common cause is road traffic accidents in order of frequency. This changing pattern of maxillofacial trauma has been reviewed by van Hoof et $\mathrm{al}^{5}$, who have compared their own longitudinal studies from the Netherlands with similar data from Hamburg and Great Britain ${ }^{5}$. In Pakistan Janjua ${ }^{4}$ has given similar data. The developed countries are showing a striking reduction in the broad category of road traffic accidents due to well trained public transport drivers and well arrange seating capacities of public transported and seat belt legislation is also strictly followed which leads to decrease incidents of road traffic accidents involving highway and intercity roads. In our study teenagers sustain more maxillofacial injuries, mostly motorcycle, mini buses and vehicle drivers as they are not following road traffic legislations. Road conditions are also not improved according to ratio of population, low utilization of safety belt, safety devices, over speed, over loading and illiteracy were found common causes of road traffic accidents in our society.

\section{CONCLUSION}

In this part of the country, Road Traffic Accidents mostly involved front seat passenger of motor car, 
motor bike drivers and passengers are the most common cause of maxillofacial fractures. According to information provided by injured persons accidents happens due to heavy traffic load, using mobile phone while driving (distracted driving), speeding, reckless driving, underage drivers, wrong way driving, unsafe lane changing, improper turns, potholes in the street and street racing all are responsible for road traffic accidents. There is a clear need of conducting continuing education programs for road user about the road safety and compulsory seat belt for four wheel vehicle passengers and helmet legislation for front as well as back seat motorcycle passengers which will decrease the possibility of incidence of maxillofacial trauma in our society.

\section{REFERENCES}

1. Siber S, Matijević M, Sikora M, et al. Assessment of Oro-Maxillofacial Trauma According to Gender, Age, Cause and Type of the Injury. Acta Stomatol Croat. 2015;49 (4):340-7.

2. Panourias IG, Skiadas PK, Sakas DE, Marketos SG. Hippocrates: a pioneer in the treatment of head injuries. Neurosurgery. 2005;57(1):181-9.

3. Kadkhodaie $\mathrm{MH}$. Three-year review of facial fractures at a teaching hospital in northern Iran. Br J Oral Maxillofac Surg. 2006;44(3):229-31.

4. Janjua OS, Ahmed W, Ibrahim MW, et al. Aetiology and pattern of dentoalveolar injuries in patients at Armed Forces Institute of Dentistry, Rawalpindi.Pak Armed Forces Med J 2011;61 (3):405-8.
5. Van Hoof RF, Merkx CA, Stekelenburg EC. The different patterns of fractures of the facial skeleton in four European countries. Int J Oral Surg. 1977; 6(1):3-11.

6. Hutchison IL, Magennis P, Shepherd JP, Brown AE. The BAOMS United Kingdom survey of facial injuries part 1. aetiology and the association with alcohol consumption. British Association of Oral and Maxillofacial Surgeons. $\mathrm{Br} \mathrm{J}$ Oral Maxillofac Surg. 1998; 36(1):3-13.

7. Ashar A, Kovacs A, Khan S, Hakim J. Blindness associated with midfacial fractures. J Oral Maxillofac Surg. 1998; 56(10):1146-50.

8. Abbas I, Ali K, Yaqoob, Mirza YB. Spectrum of Mandibular Fractures at a Tertiary Care Dental Hospital in Lahore. J Ayub Med Coll Abottabad 2003;15(2):12-4.

9. Adebayo ET, Ajike OS, Adekeye EO. Analysis of the pattern of maxillofacial fractures in Kaduna, Ni geria. Br J Oral Maxillofac Surg. 2003;41(6):396400.

10. Zakai MA, Islam T, Memon S, Aleem A. The pattern of Maxillo-Facial injuries received at Abbasi Shaheed Hospital, KMDC, Karachi. Ann Abbasi Shaheed Hosp Karachi Med Dent Coll 2002;7:291-3.

11. Bataineh $A B$. Etiology and incidence of maxillofacial fractures in the north of Jordan. Oral Surg Oral Med Oral Pathol Oral Radiol Endod. 1998;86 (1):31-5.

12. Cheema SA. Gunshot trauma of the maxillofacial region: an analysis of 66 cases. Pak J Surg 2006; 22(2):86-90.

AUTHOR AFFILIATION:
Dr. Razia Sultana (Correspondence Author)
Lecturer, Institute of Dentistry
Liaquat University of Medical and Health Sciences
(LUMHS). Jamshoro, Sindh-Pakistan.
E-mail: muhammad.rizwan@lumhs.edu.pk
Dr. Qamer un Nisa
Assistant Professor, Institute of Dentistry
LUMHS. Jamshoro, Sindh-Pakistan.
Dr. Muhammad Rizwan Memon
Assistant Professor, Institute of Dentistry
LUMHS. Jamshoro, Sindh-Pakistan.
Dr. Shahnila Shaikh
Lecturer, Institute of Dentistry
LUMHS. Jamshoro, Sindh-Pakistan.

